\begin{tabular}{|c|c|c|c|}
\hline \multirow{3}{*}{$\begin{array}{r}\text { Case Reports in } \\
\text { Gastroenterology }\end{array}$} & Case Rep Gastroenterol 20 & & \multirow[b]{2}{*}{$\begin{array}{l}\text { Karger } \\
\text { Open'access }\end{array}$} \\
\hline & $\begin{array}{l}\text { DOI: } 10.1159 / 000488193 \\
\text { Published online: August 21, } 2018\end{array}$ & $\begin{array}{l}\text { ( } 2018 \text { The Author(s) } \\
\text { Published by S. Karger AG, Basel } \\
\text { www.karger.com/crg }\end{array}$ & \\
\hline & $\begin{array}{l}\text { This article is licensed under th } \\
\text { International License (CC BY-NC) } \\
\text { Usage and distribution for commer }\end{array}$ & $\begin{array}{l}\text { nons Attribution-NonCommercial } 4.0 \\
\text { ger.com/Services/OpenAccessLicense) } \\
\text { uires written permission. }\end{array}$ & \\
\hline
\end{tabular}

\title{
Recurrent Mantle Cell Lymphoma Presenting as Gastrointestinal Bleeding
}

\author{
Rafeeq Ahmed $^{\mathrm{a}} \quad$ Kishore Kumar $^{\mathrm{a}} \quad$ Jasbir Makker $^{\mathrm{a}} \quad$ Masooma Niazi $^{\mathrm{b}}$ \\ Bhavna Balar ${ }^{\mathrm{a}}$ \\ aDivision of Gastroenterology, Department of Medicine, BronxCare Hospital Center, \\ Bronx, NY, USA; 'bepartment of Pathology, BronxCare Hospital Center, Bronx, NY, USA
}

\section{Keywords}

Mantle cell lymphoma $\cdot$ Gastrointestinal bleeding $\cdot$ Recurrence

\begin{abstract}
Mantle cell lymphoma is a rare and aggressive subtype of B-cell non-Hodgkin lymphomas. Mantle cell lymphoma frequently involves extranodal sites, and gastrointestinal tract is involved microscopically and macroscopically in more than $80 \%$ of cases. We present two cases of recurrent mantle cell lymphoma presenting with lower and upper gastrointestinal bleeding, respectively. A 58-year-old woman with a history of recurrent mantle cell lymphoma treated with chemotherapy and stem cell transplantation presented with left-sided abdominal pain and hematochezia. Colonoscopy showed a mass-like lesion in the ascending colon, polyps in the ascending colon, and splenic flexure. A 68-year-old man with a history of mantle cell lymphoma treated with chemotherapy presented with epigastric pain and melena. Esophagogastroduodenoscopy showed a large polypoidal ulcerated mass with oozing in the duodenal bulb. Biopsies in both patients were suggestive of mantle cell lymphoma. Patients with mantle cell lymphoma could be asymptomatic or may present with abdominal pain, obstruction, diarrhea, or gastrointestinal bleeding. In patients presenting with gastrointestinal symptoms, endoscopy must be pursued and biopsies must be taken for any suspicious lesions as well as normal mucosa to exclude mantle cell lymphoma as an etiology for the lesion or symptoms. Even though there are no standard guidelines for endoscopic screening of gastrointestinal tract in asymptomatic patients, one should be aware of involvement of gastrointestinal tract in the early
\end{abstract}




\section{Case Reports in Gastroenterology}

Case Rep Gastroenterol 2018;12:379-384 DOI: $10.1159 / 000488193$

(c) 2018 www.karger.com/crg

Ahmed et al.: Recurrent Mantle Cell Lymphoma Presenting as Gastrointestinal Bleeding

course of disease or recurrent disease. Although mantle cell lymphoma is initially responsive to chemotherapy, it eventually becomes refractory with a median survival of 3-5 years.

(C) 2018 The Author(s)

Published by S. Karger AG, Basel

\section{Introduction}

Mantle cell lymphoma is a rare but aggressive subtype of B-cell non-Hodgkin lymphoma. Mantle cell lymphoma results from a malignant transformation of B lymphocytes in the outer edge of a lymph node follicle called the mantle cell zone. Mantle cell lymphoma mainly involves the lymph nodes but frequently involves extranodal sites. Gastrointestinal tract is involved in more than $80 \%$ of cases. Mantle cell lymphoma is generally resistant to standard chemotherapy regimens and has a high recurrence rate. Recurrent disease is even more aggressive and resistant to treatment. We present two cases of recurrent mantle cell lymphoma presenting with lower and upper gastrointestinal bleeding.

\section{Case 1}

A 58-year-old woman presented with complaints of left-sided abdominal pain and rectal bleeding since 1 day prior to admission. Abdominal pain was described as severe, 8/10 in intensity, and continuous with no radiation. Rectal bleeding was described as bright red, mixed with stool and on wiping. She had on and off rectal bleeding since 1 year. She also complained of nausea. She denied fever, vomiting, diarrhea, constipation, hematemesis, or weight loss. She has a history of asthma, osteoarthritis, and mantle cell lymphoma diagnosed by axillary lymph node biopsy 2 years ago. She was treated with Hyper-CVAD regimen (hyperfractionated cyclophosphamide, vincristine, doxorubicin [adriamycin], dexamethasone, methotrexate, and cytarabine) and stem cell transplantation at that time. She had a relapse 1 year after initial treatment, for which she was again treated with bortezomib based chemotherapy. During this admission, her physical examination did not reveal any lymphadenopathy. Abdominal examination was significant for left lower quadrant tenderness without guarding, rigidity, or hepatosplenomegaly. Laboratory tests including her complete blood cell counts were normal. Computed tomography scan of the abdomen showed ascending colon wall thickening. She subsequently underwent colonoscopy, which showed a mass-like lesion in the ascending colon, polyps in the ascending colon as well as splenic flexure (Fig. 1a). The biopsy of all three lesions showed atypical lymphocytes infiltrating the lamina propria (Fig. 2a). The tumor cells were positive for cyclin-D1, CD5, CD20, CD43, and CD79A, and negative for CD3 and CD10 antibodies, consistent with the diagnosis of mantle cell lymphoma (Fig. 3).

\section{Case 2}

A 68-year-old man presented with complaints of epigastric pain and passing dark stools since 1 week prior to admission. Epigastric pain was described as severe, 9/10 in intensity, and continuous with no radiation. The patient complained of two episodes of vomiting, which was non-bilious and non-bloody. He complained of passing dark stools since 1 week. He denied fever, diarrhea, constipation, or weight loss. He denies taking any nonsteroidal anti-inflammatory medications. The patient has a history of diabetes mellitus, hypertension, chronic 


\section{Case Reports in Gastroenterology}

Case Rep Gastroenterol 2018;12:379-384

DOI: $10.1159 / 000488193$

(c) 2018 The Author(s). Published by S. Karger AG, Basel www.karger.com/crg

Ahmed et al.: Recurrent Mantle Cell Lymphoma Presenting as Gastrointestinal Bleeding

kidney disease, and mantle cell lymphoma diagnosed by gastric biopsy 5 years ago. The patient received RCHOP (rituximab, cyclophosphamide, hydroxydaunomycin, oncovin [vincristine], prednisone) and bendamustine-based chemotherapy 3 years ago. On examination, the patient had no lymphadenopathy. Abdominal examination was significant for epigastric tenderness without guarding, rigidity, or hepatosplenomegaly. Rectal examination showed melena. Laboratory tests were significant for hemoglobin of $6.7 \mathrm{~g} / \mathrm{dL}$ (baseline $13.3 \mathrm{~g} / \mathrm{dL}$ ) and blood urea nitrogen of $77 \mathrm{mg} / \mathrm{dL}$. Upper gastrointestinal bleeding was suspected and the patient underwent emergent esophagogastroduodenoscopy, which showed a large polypoidal ulcerated mass with oozing in the duodenal bulb (Fig. 1b). Oozing from the ulcerated mass was treated with argon plasma coagulation. The patient underwent repeat endoscopy for biopsy of duodenal mass after 3 days, which showed atypical lymphocytes diffusely infiltrating duodenal mucosa (Fig. 2b). Pathology showed tumor cells were positive for CD5, CD20, CD43, CD79a, and cyclin-D1 and negative for CD3 and CD10 antibodies, consistent with the diagnosis of mantle cell lymphoma.

\section{Discussion}

Mantle cell lymphoma is one of the subtypes of B-cell non-Hodgkin lymphomas [1]. Mantle cell lymphoma represents $2-10 \%$ of all non-Hodgkin lymphomas [2]. Mantle cell lymphoma is derived from a subset of naive pregerminal center cells localized in primary follicles or in the mantle region of secondary follicles. Most cases of mantle cell lymphoma are associated with chromosome translocation $\mathrm{t}(11 ; 14)$. This translocation involves the immunoglobulin heavy-chain gene on chromosome 14 and the $B C L 1$ locus on chromosome 11 . The molecular consequence of translocation is overexpression of the protein cyclin-D1. On immunohistochemistry, tumor cells are characteristically CD5 and pan B-cell antigen positive (e.g., CD19, CD20, CD22) but lack expression of CD10 and CD23. Immunohistochemistry helps differentiate mantle cell lymphoma from other small B-cell lymphomas. Overall, Caucasians are at higher risk of developing non-Hodgkin lymphoma than African Americans and Asian Americans [2]. The male-to-female ratio is $4: 1$, and the age range at presentation is $35-85$ years, with median age being 60 years [2].

Most patients with mantle cell lymphoma (about 70 percent) have advanced-stage disease at diagnosis. Approximately $75 \%$ of patients initially present with lymphadenopathy, extranodal disease is the primary presentation in the remaining 25\% [3]. Common sites of extranodal involvement include spleen (45-60\%), Waldeyer's ring, bone marrow ( $>60 \%$ ), blood (13-77\%), and other extranodal sites, such as the gastrointestinal tract, breast, pleura, and orbit [3].

The reason for predilection of mantle cell lymphoma to involve the gastrointestinal tract is not clear. One theory involves the expression of the mucosal homing receptor alpha-4-beta7 by lymphoma cells in peripheral lymph nodes of patients with newly diagnosed disease [4]. Another theory includes mantle cell lymphoma could originate from naive B cells in the mantle zones of lymphoid follicles in digestive tract-associated lymphoid tissue [4]. In a study of untreated patients by Romaguera et al. [4], mantle cell lymphoma was present histologically in the lower gastrointestinal tract in 53 of 60 patients (88\%) and in the upper gastrointestinal tract in 28 of 58 patients (43\%). Microscopic evidence of mantle cell lymphoma was found in $84 \%$ of patients with macroscopically normal findings by lower endoscopy and in $45 \%$ of patients with macroscopically normal findings by upper endoscopy [4]. The endoscopic findings of the upper and lower gastrointestinal tract in the study showed normal mucosa (38-51\%), 


\section{Case Reports in Gastroenterology}

Case Rep Gastroenterol 2018;12:379-384

DOI: $10.1159 / 000488193$

(c) 2018 The Author(s). Published by S. Karger AG, Basel www.karger.com/crg

Ahmed et al.: Recurrent Mantle Cell Lymphoma Presenting as Gastrointestinal Bleeding

inflammation (2-19\%), nodules and polyps (26-43\%), ulcers (1-9\%), thickening (2-5\%), and masses $(0-3 \%)[4,5]$. Mantle cell lymphoma can also present as multiple small nodular or polypoid tumors from $2 \mathrm{~mm}$ to several centimeters in diameter, along one or more segments of the gastrointestinal tract, with or without normal intervening mucosa known as multiple lymphomatous polyposis [6]. In another study by Salar et al. [7], abnormal mucosa was identified in 38\% of cases by upper endoscopy (mainly mild nonspecific gastritis) and in 54\% of cases by lower endoscopy (mostly micropolyps). Histologically, infiltration by mantle cell lymphoma was demonstrated in the stomach in $77 \%$ of cases and in the colon in $77 \%$ of cases [7]. As a whole, $92 \%$ of patients showed upper or lower gastrointestinal tract infiltration by mantle cell lymphoma [7]. Histologic evidence of mantle cell lymphoma involvement was present in all cases with endoscopically abnormal mucosa, but it was also observed in two-thirds of cases with endoscopically unremarkable mucosa [7].

Patients with mantle cell lymphoma and gastrointestinal involvement could be asymptomatic or may present with abdominal pain, obstruction, diarrhea, melena, or hematochezia. The most common site of involvement in the gastrointestinal tract is the ileocecal region, but any other area may be involved from the stomach to the rectum. Up to $26 \%$ of patients presented with gastrointestinal symptoms at the time of diagnosis in the study reported by Romaguera et al. [4]. Diagnosis is usually pursued by tissue biopsy and immunohistochemistry. Immunohistochemistry shows tumor cells positivity for cyclin-D1, CD5, CD20, CD43, and CD79A and negativity for CD3 and CD10 antibodies. Cytogenetic detection of $t(11 ; 14)$ translocation can be a useful adjunct test.

The main treatment modality for mantle cell lymphoma is combination chemotherapy. Surgery is rarely needed except for palliation in patients presenting with bowel obstruction. Although $50-90 \%$ of these patients respond to combination chemotherapy, relatively few (30\%) have a complete response [2]. Despite response rates of 50-70\% with many regimens, mantle cell lymphoma typically progresses after chemotherapy. Combination chemotherapy regimens used for treatment include CVP (cyclophosphamide, vincristine, prednisone) and CHOP (cyclophosphamide, hydroxydaunomycin, Oncovin [vincristine], prednisone) regimen, hyper-CVAD (hyperfractionated cyclophosphamide, vincristine, doxorubicin [adriamycin], dexamethasone, methotrexate, and cytarabine) with or without rituximab, hyper-CVAD with autologous stem cell transplantation, R-CHOP (CHOP plus rituximab), and single alkylating agents like chlorambucil [2]. Salvage therapies like bortezomib, lenalidomide, and ibrutinib have been used for relapsed and refractory disease [2]. Median time to treatment failure is less than 18 months [2]. The median survival time is approximately 3 years (range, 2-5 years); the 10 -year survival rate is only $5-10 \%$ [2].

In summary, mantle cell lymphoma can involve gastrointestinal tract microscopically and macroscopically in more than $80 \%$ of cases. Endoscopic findings may include normal mucosa, nodules, polyps, ulcers, and masses. Patients could be asymptomatic or may present with abdominal pain, obstruction, diarrhea, melena, or hematochezia. Even though there are no standard guidelines for endoscopic screening of gastrointestinal tract in asymptomatic patients, one should be aware of involvement of gastrointestinal tract in the early course of disease or recurrent disease. Although mantle cell lymphoma is initially responsive to chemotherapy, it eventually becomes refractory with median survival of 3-5 years. Patients with obstructive tumor masses require surgical therapy, but the mainstay of treatment is chemotherapy. In patients presenting with gastrointestinal symptoms, endoscopy must be pursued and biopsies must be taken for any suspicion lesions as well as normal mucosa to exclude mantle cell lymphoma as an etiology for the lesion or symptoms. 


\section{Statement of Ethics}

The authors have no ethical conflicts to disclose.

\section{Disclosure Statement}

The authors have no conflicts of interest to declare.

\section{References}

1 Harris NL, Jaffe ES, Stein H, Banks PM, Chan JK, Cleary ML, et al. A revised European-American classification of lymphoid neoplasms: a proposal from the International Lymphoma Study Group. Blood. 1994 Sep;84(5):1361-92.

2 Abbasi MR, Joseph A Sparano MD. Mantle cell lymphoma. Medscape. emedicine.medscape.com/article/203085-overview. Updated July 31, 2015.

3 Argatoff LH, Connors JM, Klasa RJ, Horsman DE, Gascoyne RD. Mantle cell lymphoma: a clinicopathologic study of 80 cases. Blood. 1997 Mar;89(6):2067-78.

4 Romaguera JE, Medeiros LJ, Hagemeister FB, Fayad LE, Rodriguez MA, Pro B, et al. Frequency of gastrointestinal involvement and its clinical significance in mantle cell lymphoma. Cancer. 2003 Feb;97(3):586-91.

5 Kim JH, Jung HW, Kang KJ, Min BH, Lee JH, Chang DK, et al. Endoscopic findings in mantle cell lymphoma with gastrointestinal tract involvement. Acta Haematol. 2012;127(3):129-34.

6 Ruskoné-Fourmestraux A, Audouin J. Primary gastrointestinal tract mantle cell lymphoma as multiple lymphomatous polyposis. Best Pract Res Clin Gastroenterol. 2010 Feb;24(1):35-42.

7 Salar A, Juanpere N, Bellosillo B, Domingo-Domenech E, Espinet B, Seoane A, et al. Gastrointestinal involvement in mantle cell lymphoma: a prospective clinic, endoscopic, and pathologic study. Am J Surg Pathol. 2006 Oct;30(10):1274-80.
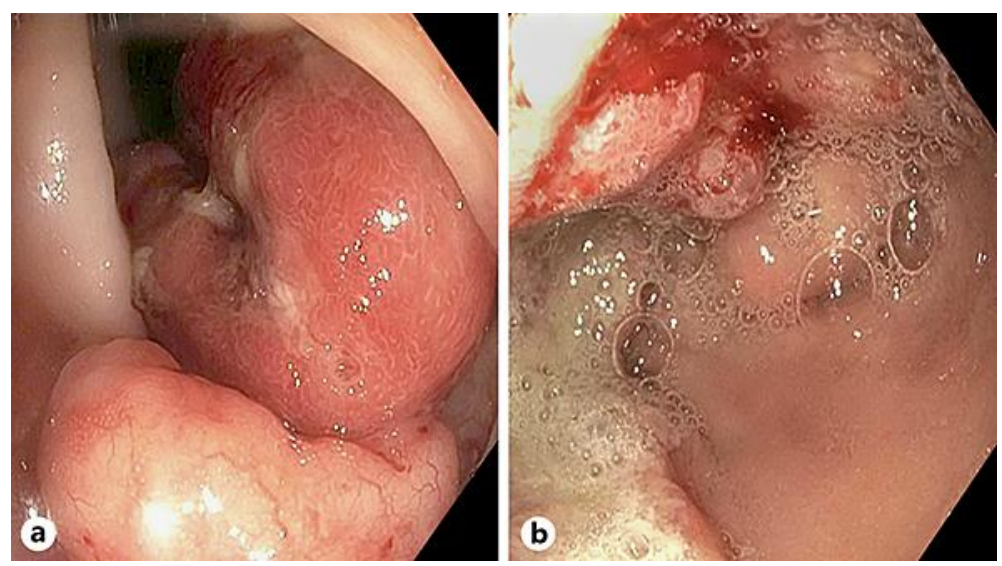

Fig. 1. a Colonoscopy showing a mass-like lesion in ascending colon and polyp. b Esophagogastroduodenoscopy showing large polypoidal ulcerated mass with oozing in the duodenal bulb. 


\section{Case Reports in Gastroenterology}

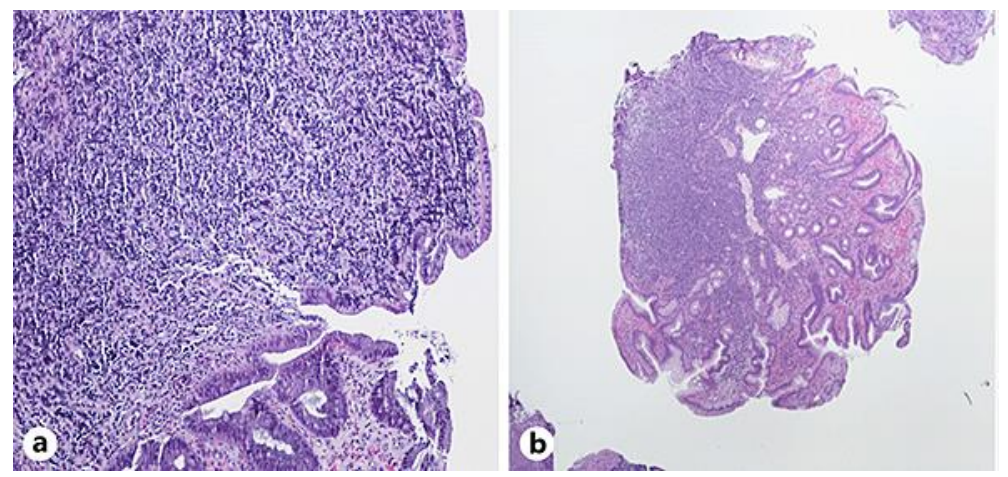

Fig. 2. a Mantle cell lymphoma involving the colonic mucosa with architectural effacement (H\&E, magnification $\times 200$ ). $\mathbf{b}$ Mantle cell lymphoma with infiltration of duodenal mucosa. The lymphomatous infiltration is diffuse $(\mathrm{H} \& \mathrm{E}$, magnification $\times 100)$.

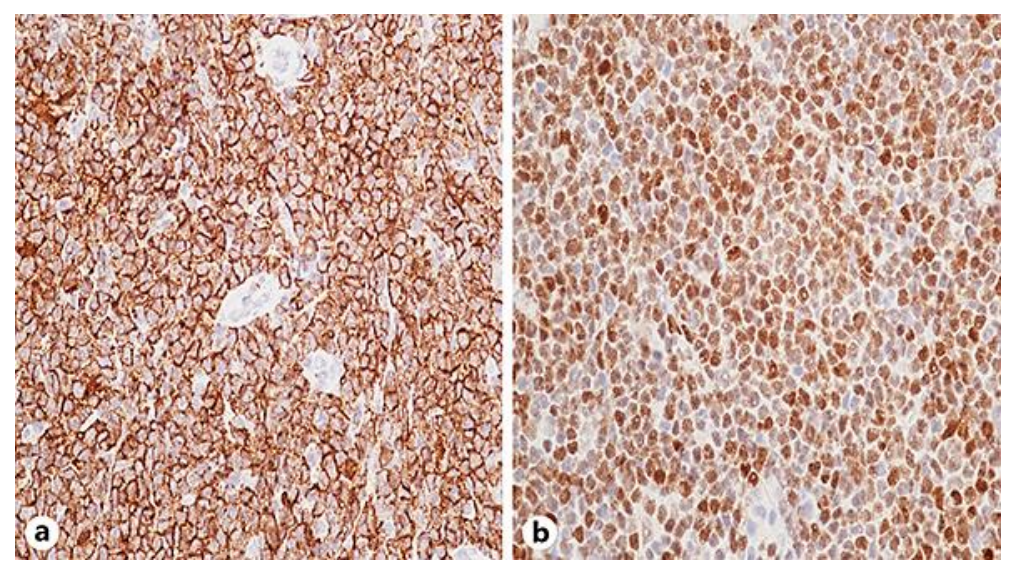

Fig. 3. a Mantle cell lymphoma: positive immunoreactivity with CD20 and negative for CD3 and CD10 (immunohistochemical stain, magnification $\times 400$ ). b Mantle cell lymphoma: cyclin-D1 immunostain shows nuclear expression in the lymphoma cells. The nuclei show cell-to-cell variation in the intensity of cyclinD1 expression (immunohistochemical stain, magnification $\times 400$ ). 